\title{
Effectiveness of Subgingival Scaling and Root Planing: Single Versus Multiple Episodes of Instrumentation
}

\author{
Gissela B. Anderson, ${ }^{*}$ John A. Palmer,${ }^{\dagger}$ Fred L. Bye, ${ }^{\ddagger}$ Billy A. Smith,$\$$ and Raul G. \\ Caffesse*
}

THIS STUDY EVAlUATES THE EFFECTIVENESS of subgingival scaling and root planing comparing the effect of a single instrumentation to the effect of three instrumentations. A total of 35 teeth in 15 patients were selected; 15 were scaled once (Group A), 15 were scaled three times (Group B), and 5 were used as controls (Group C), representing teeth that were not instrumented. The Group A and B teeth were chosen in the same patient based on random selection. All the teeth were scored by the calculus index of the periodontal disease index. Six surface locations were probed to determine probing depth. The level of the gingival margin was marked on the teeth to locate supra- and subgingival calculus after extraction. The Group A and B teeth received the initial episode of scaling and root planing for not more than 10 minutes, then only the Group B teeth received two additional instrumentations of not more than 5 minutes each. The additional instrumentations were performed 24 hours after the initial scaling. The scaled and control teeth were extracted immediately after the third instrumentation period. The teeth were washed with water and stained with methylene blue. They were viewed under a stereomicroscope which had a tenth grid on its eyepiece. Assessments were made involving the total counts and percents of the surfaces covered with calculus on the scaled and unscaled teeth. The results demonstrated no significant difference in the effectiveness of calculus removal between single and multiple episodes of scaling and root planing. Similar results were found for the total amount of calculus removed, the calculus removed from individual surfaces, and the calculus removed from various probing depth levels. J Periodontol 1996;67:367-373.

Key Words: Dental calculus/prevention and control; planing/instrumentation; planing/ methods; scaling/instrumentation; scaling/methods.

Bacterial deposits that include calculus have been firmly established as the most important factors in the development of periodontal disease. ${ }^{1-4}$ Clinical investigations have shown that the removal of subgingival calculus from the root surface significantly reduces gingivitis, ${ }^{5}$ tooth loss, ${ }^{5-6}$ attachment loss, ${ }^{7-10}$ severity of disease, ${ }^{10-11}$ and probing depth ${ }^{10-15}$ along with improvement in many other clinical parameters.

The effectiveness of a single episode of closed gingival scaling and root planing in removing calculus is limited, as has been demonstrated by many researchers. ${ }^{16-22}$ This

*The University of Texas, Health Science Center, Dental Branch, Department of Stomatology, Division of Periodontics, Houston, TX.

"Private practice, Wheeling, WV.

‡Private practice, Hagerstown, MD.

sDepartment of Periodontics/Prevention and Geriatrics, School of Dentistry, The University of Michigan, Ann Arbor, MI. would indicate that other more invasive procedures would be required to allow for a calculus free surface. Indeed, surgical procedures have been shown to be more effective in removing calculus, but by no means provide complete removal of all accretions. ${ }^{20,23-28}$

While periodontal surgery is an effective mode of treatment, non-surgical periodontal therapy is the first line of treatment in the majority of cases of periodontitis. ${ }^{29}$ It is possible that repeated instrumentation could lead to more successful results than single root planing episodes without invasive efforts. Repeated instrumentation may be required to insure complete debridement of plaque, calculus, and root surface contaminants and, therefore, achieve more optimal results. Badersten et al..$^{30}$ showed that there was no difference between single and multiple instrumentation when assessed by clinical parameters.

When determining the effectiveness of single and mul- 
tiple instrumentations, measurement of residual calculus deposits is a more direct and objective measure than changes in clinical parameters.

If repeated instrumentation can be obviated, a significant reduction in time of active therapy will be accomplished. On the other hand, if repeated instrumentation appears significantly more beneficial, the need for more invasive techniques could be reduced in some cases. Thus, it was necessary to determine that three episodes of root planing are as effective as one.

The purpose of this study was to quantitatively evaluate the effectiveness of calculus removal in single and multiple instrumentations.

\section{METHODS AND MATERIALS}

\section{Selection of Patients}

Fifteen patients ( 10 male, 5 female), with ages ranging from 27 to 73 years old and who were scheduled for immediate complete denture treatment or whose teeth were to be extracted due to periodontal disease, were selected for this study. The patients had to have at least two teeth of any type scheduled for extraction in order to participate. None of these patients had previously received any periodontal treatment besides routine prophylaxis at a dentist office. After explaining the purpose, benefits, and risks of the study to the patient, they were asked to sign a consent form. The protocol was approved by the institutional review committee for human subjects of The University of Michigan.

\section{Selection of Teeth}

All tooth types except third molars were included in the investigation. Calculus was measured on the four external surfaces of the teeth (buccal, lingual, mesial, and distal). However, in order to participate in the study, the patient had to have at least two teeth with a periodontal disease index calculus score ${ }^{31}$ of 2 or more. This ensured the same relative magnitude of initial subgingival calculus. If a third tooth satisfying the same criterion was available, it served as a control. Taking into consideration that a previous study employing the same technique already compared a single episode of scaling and root planing to controls receiving no instrumentation, ${ }^{21}$ controls were used in the present study only to illustrate the state of noninstrumented teeth. The total number of teeth was 35 (15 scaled once, 15 scaled three times, and 5 controls).

\section{Measurements}

Dental calculus was assessed according to the periodontal disease index (PDI). ${ }^{31}$

A CP-11 probell or a \#3 explorerl was used for the detection of subgingival calculus. Probing depth was mea-

"Hu-Friedy Manufacturing, Inc., Chicago, IL. sured from the free gingival margin to the bottom of the periodontal pocket of the experimental and control teeth. Probing measurements were made at six locations on each tooth and rounded to the nearest millimeter; however, measurements close to $0.5 \mathrm{~mm}$ were rounded to the lower whole number. The distobuccal, buccal, mesiobuccal, distolingual, lingual, and mesiolingual aspects of each individual tooth were scored separately. The buccal and lingual measurements were made on the midline of each tooth. The rest of the measurements were made as close as possible to the interproximal contact areas of the teeth with the probe pointed in an axial direction.

\section{Experimental Procedure}

The experimental procedures were performed in the following order:

1. Review of the patient's medical history.

2. PDI calculus scoring.

3. Probing depth measurements.

4. Following local anesthesia, the teeth were marked circumferentially at the level of the free gingival margin with a high speed handpiece and an inverted cone bur.

5. Two experimental teeth on each patient (Group A and B) were scaled and root planed thoroughly. Each tooth was instrumented for not more than 10 minutes or until a smooth root surface was detected along the entire root coronal to the depth of the pocket using the probe or the explorer. The control tooth (Group $\mathrm{C}$ ) was not instrumented.

6. The patient returned in not less than 24 hours for the second episode of scaling and root planing on one of the experimental teeth determined randomly at that time and thereafter designated as Group B. The Group B tooth was instrumented in the same manner not exceeding 5 minutes in duration. Neither the other experimental tooth (Group $\mathrm{A}$ ) or the control tooth received further instrumentation.

7. After a period not less than 24 hours after the second instrumentation the patient received a third episode of scaling and root planing on the Group B tooth, also not exceeding 5 minutes in duration; all the teeth (Groups $\mathrm{A}, \mathrm{B}$, and C) were then immediately extracted.

\section{Preparation of Teeth}

Teeth were immediately rinsed with running water to remove surgical hemorrhage. Soft tissue tags were removed, and the teeth transferred to $1 \%$ methylene blue for 2 minutes. This solution stained the connective tissue and remaining calculus. Finally the teeth were rinsed with running water for 2 to 3 minutes.

\section{Assessment of Residual Calculus Under the Stereomicroscope}

The same methodology previously described ${ }^{21}$ was followed for the assessment of residual calculus. The teeth 


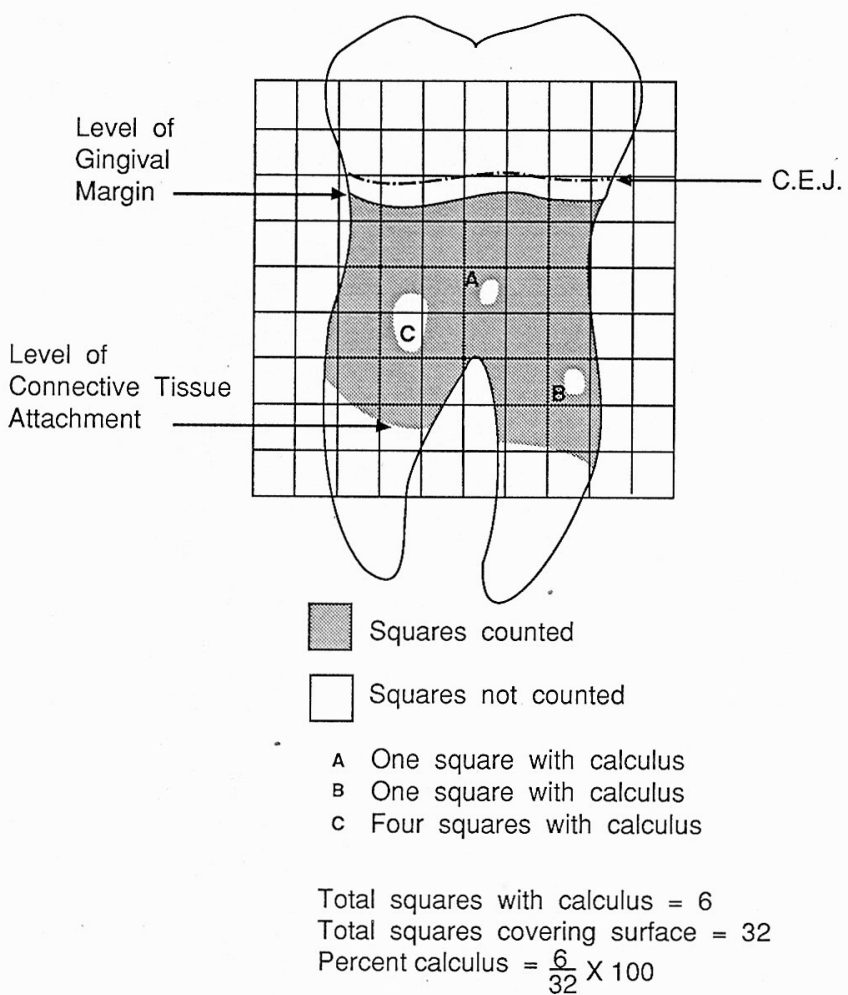

Figure 1. Assessment of calculus under microscope (from Rabbani et $\left.a l^{21}\right)$.

were viewed under a stereomicroscope $e^{\text {f }}$ with a magnification of 6.3/12.5. The calculus was measured on four surfaces (buccal, lingual, mesial, and distal) using a micrometer disc," $10 \mathrm{~mm} \times 10 \mathrm{~mm}$ square subdivided into 100 squares, which was placed on the eyepiece** of the stereomicroscope. The four surfaces were separated by placing a small scratch with a curet on each line angle of the tooth, from the areas of the gingival landmark (bur mark) to the line of the connective tissue attachment. Based on the view in the stereomicroscope, the total number of squares which covered each surface of the tooth from the connective tissue attachment to the free gingival margin scratch were added. The number of squares with calculus for each of the surfaces were then counted and added. This represented the total number of squares with calculus. From these numbers, percents and total counts of calculus remaining could be obtained. In the assessment of calculus, the presence of calculus in each square of the tenth grid was counted as one, even if it was a very small fragment (Fig. 1). All measurements were performed by the same examiner at different times and were highly reproducible.

TJ.M. Stereomicroscope, Olympus Optical Co., Ltd, Tokyo, Japan. "Whipple Net Micrometer Disc, Olympus, WA.

**WFX Micro-Optics Co., Southfield, MI.
Table 1. Percent Residual Calculus Scores for Each Treatment Group for All Surfaces

\begin{tabular}{|c|c|c|c|c|}
\hline & $\mathrm{N}$ & Range/Surface & Mean/Surface & SD \\
\hline $\begin{array}{l}\text { Scaled } 1 \times \\
\quad(\text { Group A) }\end{array}$ & 15 & $11.6-32.8 \%$ & $25 \% \quad] *$ & 6 \\
\hline $\begin{array}{l}\text { Scaled } 3 \times \\
\quad(\text { Group B) }\end{array}$ & 15 & $11.5-44.8 \%$ & $23.7 \%$ & 8 \\
\hline $\begin{array}{l}\text { Control } \\
\text { (Group C) }\end{array}$ & 5 & $55.6-76.9 \%$ & $70 \%$ & 8.6 \\
\hline
\end{tabular}

\section{Statistical Analysis}

MIDAS (Michigan Interactive Data Analysis System) was used to test the hypothesis that there was no difference in the effectiveness of one and three episodes of subgingival scaling and root planing. The study was designed to compare teeth scaled once, teeth scaled three times, and non-scaled control teeth in terms of the percent of calculus and total counts of calculus left on the surfaces of each experimental group.

The statistical tests utilized to evaluate the data were the paired $t$-test and the Student $t$-test.

When attempting to relate calculus scores and probing depth the following modification was performed: the probing depth was measured at six locations on each tooth (buccal, lingual, mesiobuccal, mesiolingual, distobuccal, distolingual). However, the percentage and total counts of calculus remaining were computed for four surfaces of each tooth (buccal, lingual, mesial, distal) under the stereomicroscope. In order to make the probing depth measurements and the calculus scores comparable for a given surface, the average of mesiobuccal and mesiolingual and also the average of distobuccal and distolingual probing depth measurements were calculated and the means used for the comparison with calculus scores for these surfaces.

\section{RESULTS}

The results of one and three episodes of scaling and root planing and control teeth were analyzed according to percents and total counts of residual calculus. Assessments of calculus scores were also made in various probing depth categories.

There were no differences between Groups A, B, and $\mathrm{C}$ in terms of calculus scores at baseline. This was a criterion of tooth selection. The two or three teeth (when a control was available) used from each patient all possessed the same calculus score. A description of percent residual calculus scores for the three groups is presented in Table 1. It can be observed that the range and mean values per surface for scaled teeth (Group A and B) are very similar, while the same values for the control group are much higher. This can be observed in Figure 2. Comparisons of percent residual calculus scores between the Group A teeth and the controls (Group C) show that 


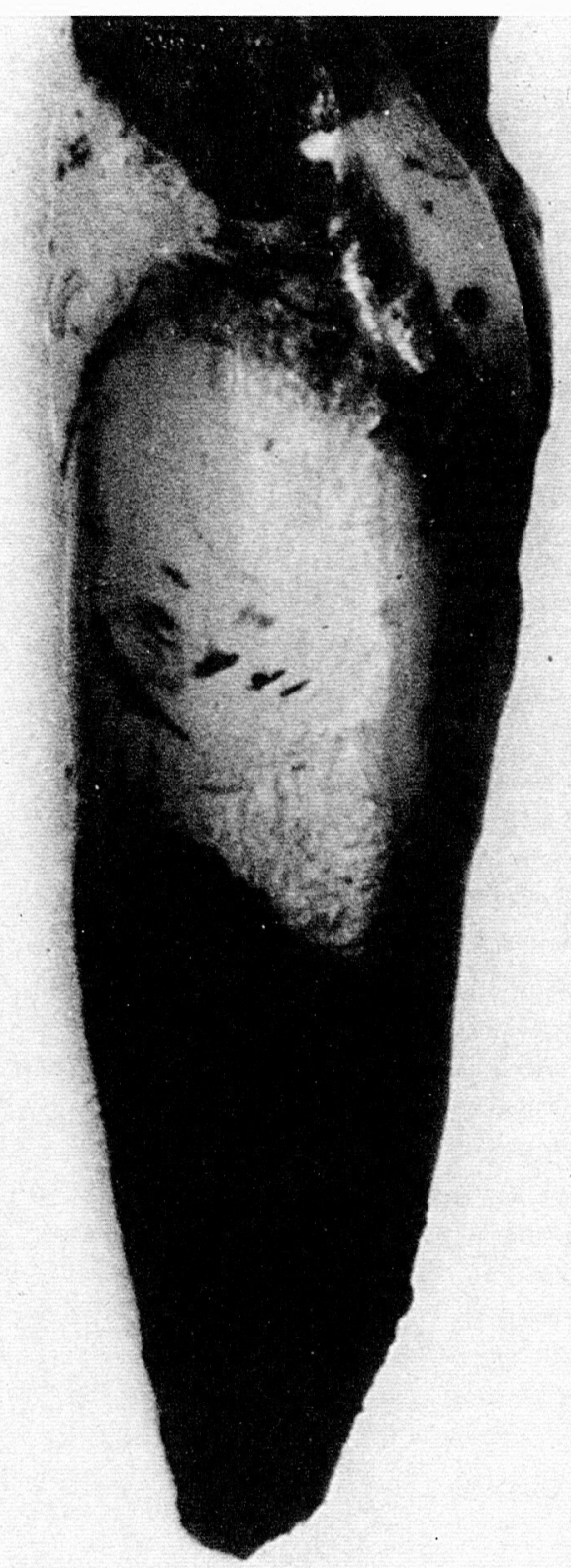

Figure 2. A. Photograph of a typical root surface evaluated from Group A (instrumented once).

Group A teeth had a significantly lower percent of calculus than the control. A similar result was found between Group B and the controls. Therefore, scaling had an obvious, significant effect in reducing the percent of residual calculus. Table 2 shows results comparing the group scaled one time (Group A) to the group receiving three instrumentations (Group B). There was no significant difference between the two groups when surfaces were totaled together, or when each surface (mesial, buccal, distal, lingual) was evaluated individually.

Assessments were made using total counts to further

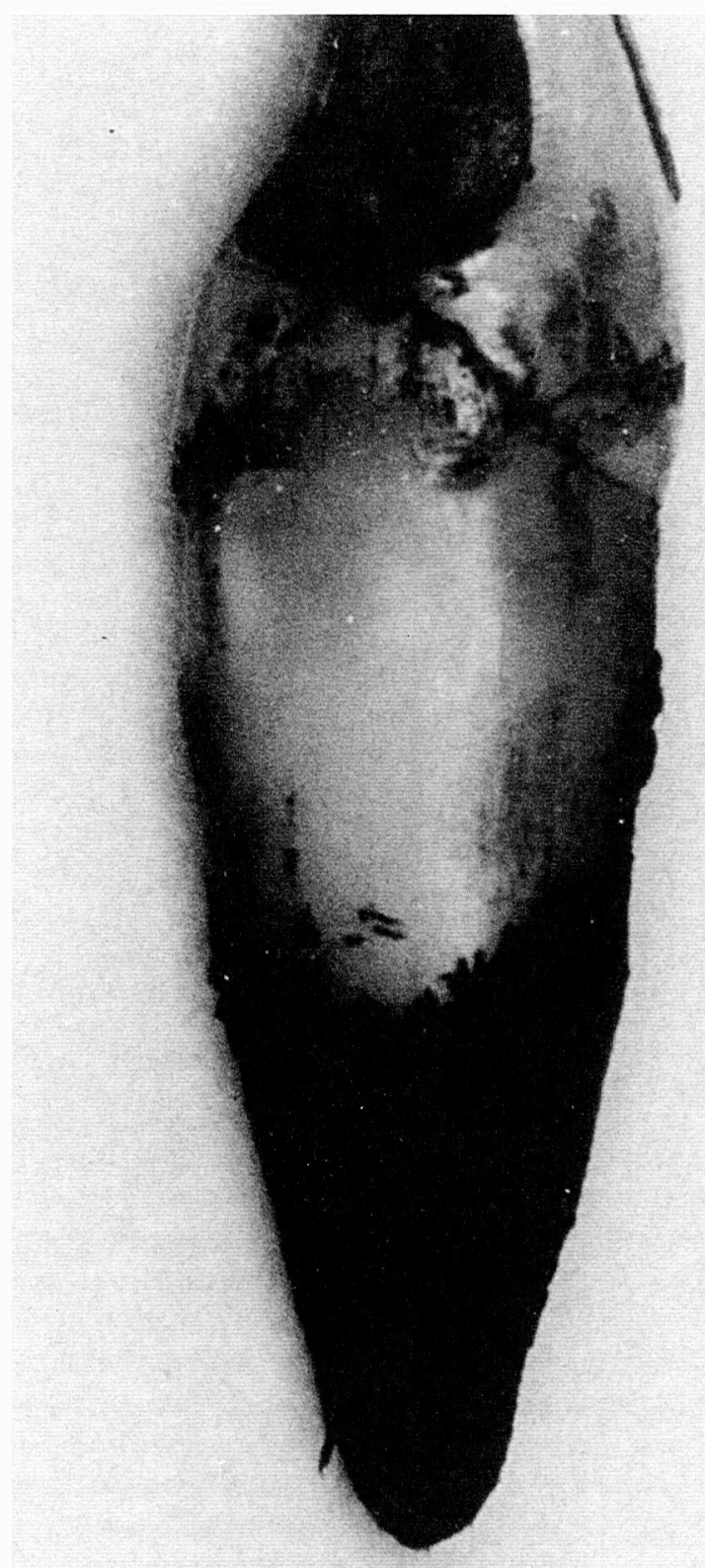

Figure 2. B. Photograph of a typical root surface evaluated from Group $B$ (scaled three times). Although surface appears smoother, remaining calculus is also seen.

determine the amount of residual calculus of the scaled treatment groups. Table 3 describes the data using total counts of residual calculus. It shows a large difference in calculus scores between the scaled teeth and the controls. Range and mean values of total counts per surface are much larger in the control group receiving no scaling and root planing. However, data presented in Table 4 show no significant difference in total count values when comparing the group that received scaling one time and the group receiving three episodes of instrumentation. Significant differences could not be detected when all the surfaces in 


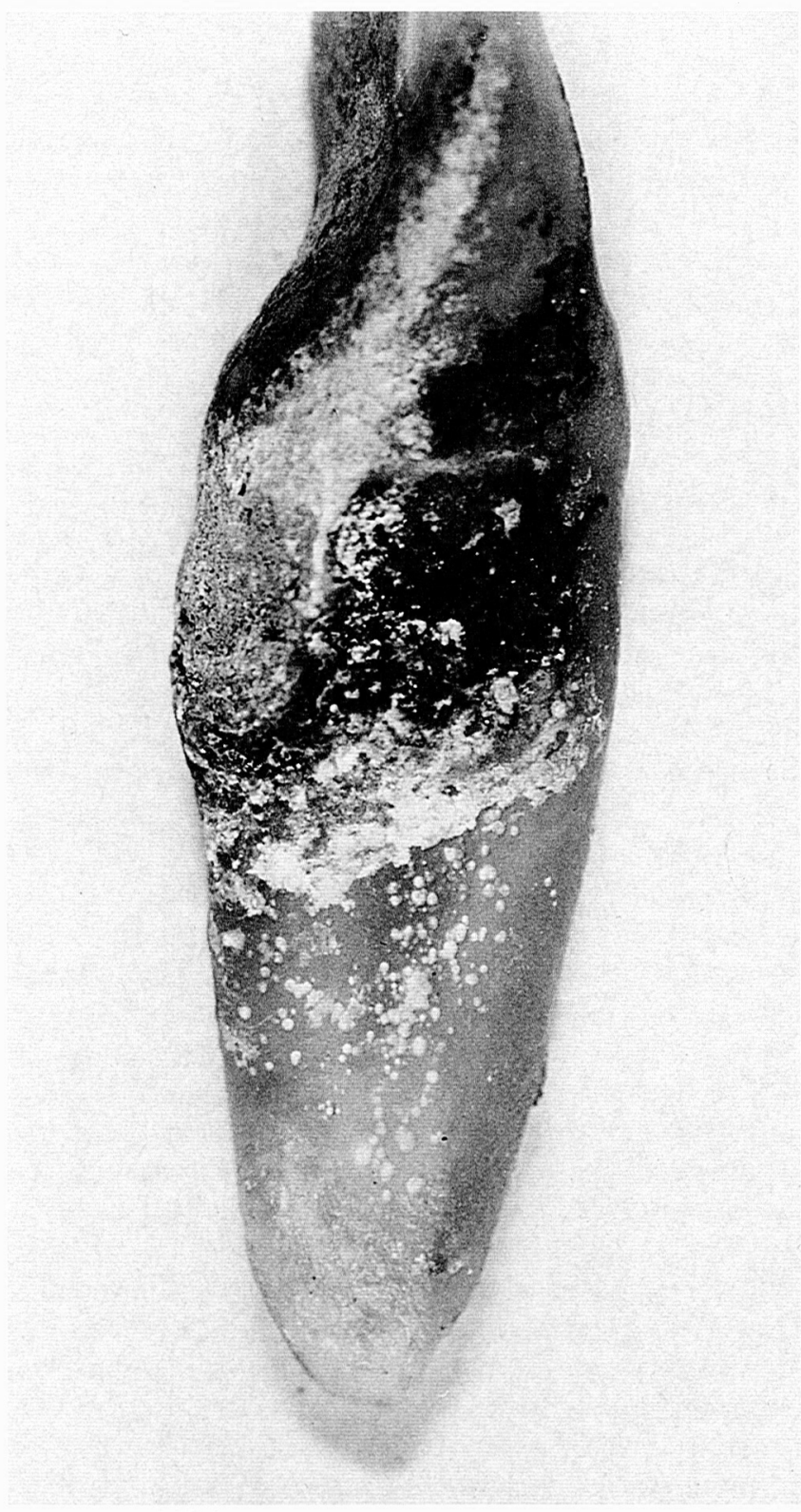

Figure 2. (continued) C. Photograph of a typical root surface evaluated from Group $C$ (control), showing more calculus present than either Figure $2 A$ or Figure $2 B$.
Table 3. Total Count Scores of Residual Calculus for Each Treatment Group

\begin{tabular}{|c|c|c|c|c|}
\hline . & $\mathrm{N}$ & $\begin{array}{l}\text { Range/ } \\
\text { Surface }\end{array}$ & Mean/Surface & $\mathrm{SD}$ \\
\hline $\begin{array}{l}\text { Scaled 1X } \\
(\text { Group A) }\end{array}$ & 15 & $2.3-9.8$ & $5.2] *$ & 2.1 \\
\hline $\begin{array}{l}\text { Scaled } 3 \times \\
\quad \text { (Group B) }\end{array}$ & 15 & $2.3-7.8$ & 4.7 & 1.9 \\
\hline $\begin{array}{l}\text { Control } \\
\text { (Group C) }\end{array}$ & 5 & $7.8-24.0$ & 13.5 & 6.5 \\
\hline
\end{tabular}

Table 4. Comparison of Total Counts of Residual Calculus for Treatment Groups A and B for Individual Surfaces and for Total Surfaces $(\mathbf{N}=15)$

\begin{tabular}{|c|c|c|c|c|c|}
\hline & \multicolumn{4}{|c|}{ Total Count Average } & \multirow[b]{2}{*}{ Total } \\
\hline & Mesial & Buccal & Distal & Lingual & \\
\hline $\begin{array}{l}\text { Scaled } 1 \times \\
\quad(\text { Group A) }\end{array}$ & 7.1 & 4.7 & 5.5 & 3.4 & 5.2 \\
\hline $\begin{array}{l}\text { Scaled } 3 \times \\
\quad \text { (Group B) }\end{array}$ & 5.8 & 4.5 & 5.1 & 3.7 & 4.7 \\
\hline Significance* & .3438 & .8713 & 6753 & .9466 & .4286 \\
\hline
\end{tabular}

*Significance is based on all scores, not limited to averages; significance determined via paired $t$-test.

each group were totaled or when each surface was analyzed individually.

Comparisons involving probing depths were also made. Table 5 describes the scores for residual calculus in various probing depth categories: 1.0 to $3.0 \mathrm{~mm}, 3.5$ to 6.0 $\mathrm{mm}$, and $\geq 6.5 \mathrm{~mm}$ for scaled treatment Groups A and B. Comparisons between percents and total counts of residual calculus are presented and show that there were no significant differences between the percent of residual calculus in Groups A and B when categorized by the various probing depths.

Observing the mean scores, Table 5 shows apparently contradictory results. Mean total count scores of residual calculus reveal that more calculus is associated with deeper pockets. As the pockets increased in depth, the amount of residual calculus became greater. However, when assessing the mean scores for the percent values of residual calculus, as the depth of the pocket increases, the percent of residual calculus decreases.

Table 2. Comparison of Percent Residual Calculus Scores for Treatment Groups A and B for Individual Surfaces and the Total Surfaces $(N=15)$

\begin{tabular}{|c|c|c|c|c|c|c|c|}
\hline & \multicolumn{4}{|c|}{ Percent Residual Calculus } & \multirow{2}{*}{$\begin{array}{c}\text { Total } \\
\text { Mean/ } \\
\text { Surface }\end{array}$} & \multirow[b]{2}{*}{$\mathrm{SD}$} & \multirow{2}{*}{$\begin{array}{l}\text { Range/ } \\
\text { Surface }\end{array}$} \\
\hline & Mesial & Buccal & Distal & Lingual & & & \\
\hline $\begin{array}{l}\text { Scaled } 1 \times \\
\quad(\text { Group A) }\end{array}$ & 22.9 & 29.2 & 20.9 & 26.8 & 25.0 & 6 & $11.6-32.8$ \\
\hline $\begin{array}{l}\text { Scaled } 3 \times \\
\quad(\text { Group B) }\end{array}$ & 22.6 & 29.7 & 18.8 & 23.5 & 23.7 & 8 & $11.5-44.8$ \\
\hline Significance* & .9461 & .9120 & .5464 & .5031 & .4909 & & \\
\hline
\end{tabular}

"Significance is based on all scores, not limited to mean values; significance determined via paired $t$-test. 
Table 5. Comparison and Percentage Calculus and Total Counts of Residual Calculus in Various Pocket Depth Categories in Treatment Groups $A$ and $B(N=15)$

\begin{tabular}{|c|c|c|c|c|}
\hline & & \multicolumn{3}{|c|}{ Probing Depth } \\
\hline & & $\begin{array}{c}1.0-3.0 \\
\mathrm{~mm}\end{array}$ & $\begin{array}{c}3.5-6.0 \\
\mathrm{~mm}\end{array}$ & $\geq 6.5 \mathrm{~mm}$ \\
\hline \multirow[t]{3}{*}{$\begin{array}{l}\text { Scaled } 1 \times \\
\quad(\text { Group A) }\end{array}$} & $\begin{array}{l}\text { Number of surfaces } \\
\text { at risk }\end{array}$ & 19 & 33 & 8 \\
\hline & $\begin{array}{c}\text { Average } \% \text { calculus } \\
\text { per root surface }\end{array}$ & 28.0 & 24.1 & 22.7 \\
\hline & $\begin{array}{l}\text { Average total count } \\
\text { per root surface }\end{array}$ & 4.5 & 5.1 & 7.0 \\
\hline \multirow[t]{3}{*}{$\begin{array}{l}\text { Scaled } 3 \times \\
\quad(\text { Group B) }\end{array}$} & $\begin{array}{l}\text { Number of surfaces } \\
\text { at risk }\end{array}$ & 25 & 26 & 9 \\
\hline & $\begin{array}{c}\text { Average } \% \text { calculus } \\
\text { per root surface }\end{array}$ & 26.1 & 22.7 & 19.7 \\
\hline & $\begin{array}{l}\text { Average total count } \\
\text { per root surface }\end{array}$ & 4.4 & $\cdot 4.5$ & 6.0 \\
\hline \multicolumn{2}{|c|}{$*$ Significance $\%$} & .7144 & .6387 & .6195 \\
\hline \multicolumn{2}{|c|}{ *Significance total count } & .9219 & .4805 & .5939 \\
\hline
\end{tabular}

*Significance determined viä Student $t$-test.

\section{DISCUSSION}

The effectiveness of scaling and root planing procedures in removing accretions from root surfaces has been clearly demonstrated by this study. Percent residual/calculus scores revealed that teeth receiving both single and multiple instrumentations had significantly less calculus than did the control teeth. Analyses were made in terms of the total surfaces in each group and when surfaces were grouped individually (mesial, buccal, distal, lingual). However, by no means were these surfaces calculus free. This is in keeping with previous reports demonstrating that complete calculus removal is technically very difficult. Using a scanning electron microscope, Jones et al. ${ }^{16}$ found numerous residual calculus deposits after in vivo scaling and root planing. Walker and $\mathrm{Ash}^{17}$ reported similar results after one instrumentation. They noted the presence of burnished calculus that was not detected clinically. Schaffer ${ }^{18}$ reported the presence of residual calculus in cemental defects post-instrumentation, while Frumker and Gardner ${ }^{19}$ felt that root surface topography made calculus removal difficult.

While this study clearly demonstrated the ability of non-surgical scaling and root planing procedures to remove calculus from root surfaces, it also showed that short-term frequency of such procedures ( 24 hours) is insignificant in relation to the effectiveness of calculus removal. Surfaces that had undergone three episodes of scaling and root planing were not significantly different from those that had a single instrumentation. This was evident in terms of both percents and total counts of residual calculus. Further evaluation of percent and total count scores showed that there was also no difference observed when assessing individual tooth surfaces (mesial, buccal, distal, lingual) nor when surfaces were grouped into various probing depth categories (Table 5).
Therefore, results of this study suggest that residual calculus not removed after one thorough episode of scaling and root planing is not likely to be removed by repeated instrumentation. Many authors have suggested various reasons for the inability of scaling and root planing procedures to routinely provide a calculus-free root surface. Some researchers attribute limited success of nonsurgical instrumentation to poor accessibility due to probing depth, ${ }^{20,21,32}$ defects in the root surface, ${ }^{16,18}$ root surface topography, ${ }^{16,18,19,33,34}$ and operator variability. ${ }^{26,27,35}$ Other authors do not feel that smoothness is the proper indicator of a "clean" root surface due to operator inability to distinguish between burnished calculus, cementum or dentin. ${ }^{17,18,21}$ In addition, Sherman et al. ${ }^{36}$ reported the difficulties encountered in determining the thoroughness of subgingival instrumentation, especially when the interexaminer and intraexaminer clinical agreement in detecting calculus was low. This study showed that problems associated with the effectiveness of single episodes of scaling and root planing will not be overcome by repeated instrumentation.

Badersten et al..$^{30}$ also evaluated the effects of single and multiple instrumentation in patients with severely advanced periodontal disease using clinical parameters. Probing depth, bleeding scores, and clinical attachment levels were used to measure the healing response. While the parameters used in that study were different from those of the present study, the results were similar. Both reports showed that no significant, measurable benefit was accomplished by repeated episodes of non-surgical scaling and root planing.

As mentioned previously, there was a discrepancy between mean percent and total counts of residual calculus as probing depth increased (Table 5). The mean total counts of remaining calculus showed a moderate increasing trend as the probing depth increased. This result is similar to those achieved by Waerhaug,,$^{20}$ Rabbani et al., ${ }^{21}$ Stambaugh et al., ${ }^{32}$ and Fleischer et al., ${ }^{27}$ who showed that larger amounts of residual calculus remained in deeper pockets. Those authors indicated that probing depth was a main determining factor in the effectiveness of root preparation. However, in this study, mean percent calculus scores showed a mild decrease with increasing probing depth. It is felt that the difference between these two trends is due to the time limitation placed on the instrumentation period for each tooth. Teeth that were scaled one time were not instrumented more than 10 minutes while teeth scaled three times were not root planed more than a total of 20 minutes. Because of these limitations, more instrumentation was performed in the deepest portion of pockets with more surface area harboring calculus. Since more surface area was instrumented, the percent scores for these deeper pockets were lower, even though they actually had more calculus as evidenced by the total count scores. It is, therefore, felt that the mean total count 
scores are a truer representation of the calculus associated with increasing probing depth. Another observation was the clinical healing and decrease in inflammation seen in some patients even a short time after initial instrumentation.

\section{Conclusions}

Based on this study, we conclude that: 1) single and multiple episodes of scaling and root planing significantly reduced the amount of calculus on root surfaces; and 2) there is no significant difference in the effectiveness of calculus removal between single and multiple episodes of scaling and root planing within 24 hours, without allowing for possible probing depth reduction.

\section{REFERENCES}

1. Lovdal A, Arno A, Waerhaug J. Incidence of clinical manifestations of periodontal disease in light of oral hygiene and calculus formation. J Am Dent Assoc 1958;56:21-33.

2. Green JC. Periodontal disease in India: Report of an epidemiological study. J Dent Res 1960;39:302-312.

3. Greene JC. Oral hygiene and periodontal disease. Am J Public Health 1963;53:913-922.

4. Löe H. Epidemiology of periodontal disease. An evaluation of the relative significance of the aetiological factors in the light of recent epidemiological research. Odont T 1963;71:479-503.

5. Lövdal A, Arno A, Schei O, Waerhaug J. Combined effect of subgingival scaling and controlled oral hygiene on the incidence of gingivitis. Acta Odontol Scand 1961;19:537-555.

6. Hirschfeld L, Wasserman B. A long-term survey of tooth loss in 600 treated periodontal patients. $J$ Periodontol 1978;49:225-237.

7. Suomi JD, Green JC, Vermillion JR, Doyle J, Chang JJ, Leatherwood EC. The effect of controlled oral hygiene procedures on the progression of periodontal disease in adults: Results after third and final year. $J$ Periodontol 1971;42:152-160.

8. Axelsson P, Lindhe J. Effect of oral hygiene procedures on caries and periodontal disease in adults. J Clin Periodontol 1978;5:133151.

9. Axelsson $\mathrm{P}$, Lindhe J. The significance of maintenance care in the treatment of periodontal disease. J Clin Periodontol 1981;8:281294.

10. Badersten A, Nilveus R, Egelberg J. Effect of non-surgical periodontal therapy. II. Severely advanced periodontitis. $J$ Clin Periodontol 1984;11:63-76.

11. Badersten A, Nilveus R, Egelberg J. Effect of non-surgical periodontal therapy: I. Moderately advanced periodontitis. J Clin Periodontol 1981;8:57-72.

12. Tagge DK, O'Leary TJ, El-Kafrawy AH. The clinical and histological response of periodontal pockets to root planing and oral hygiene. J Periodontol 1975;46:527-533.

13. Hughs TP, Caffesse RG. Gingival changes following scaling, root planing and oral hygiene. A biometric evaluation. J Periodontol 1978;49:245-252.

14. Hellden LB, Listgarten MA, Lindhe J. The effect of tetracycline and/ or scaling on human periodontal disease. J Clin Periodontol 1979;6: 222-230.

15. Proye $\mathrm{M}$, Canton J, Polson A. Initial healing of periodontal pockets after a single episode of root planing monitored by controlled probing forces. J Periodontol 1982;53:296-301.
16. Jones SJ, Lozdan J, Boyde A. Tooth surfaces treated in situ with periodontal instruments. Scanning electron microscopic studies. $\mathrm{Br}$ Dent $J$ 1972;132:57-64.

17. Walker SL, Ash MM. A study of root planing by scanning electron microscopy. Dent Hyg 1976;50:109-114.

18. Schaffer EM. Histological results of root curettage of human teeth. $J$ Periodontol 1956;27:296-300.

19. Frumker SC, Gardner WM. The relation of the topography of the root surface to the removal of calculus. J Periodontol 1956;27:292295.

20. Waerhaug J. Healing of the dentoepithelial junction following subgingival plaque control. I. As observed in human biopsy material. J Periodontol 1978;49:1-8.

21. Rabbani GM, Ash MM, Caffesse RG. The effectiveness of subgingival scaling and root planing in calculus removal. $J$ Periodontol 1981;52:119-123.

22. Waerhaug J. Healing of the dentoepithelial junction following subgingival plaque control. II. As observed on extracted teeth. J Periodontol 1978;49:119-134.

23. Caffesse RG, Sweeney PL, Smith BA. Scaling and root planing with or without periodontal flap surgery. J Clin Periodontol 1986;13: 205-210.

24. Eaton KA, Kieser JB, Davies RM. The removal of root surface deposits. J Clin Periodontol 1985;12:141-152.

25. Waerhaug $\mathbf{J}$. A method of evaluation of periodontal problems on extracted teeth. J Clin Periodontol 1975;2:160-168.

26. Brayer WK, Mellonig JT, Dunlap RM, Marinak KW, Carson RE. Scaling and root planing effectiveness: The effect of root surface access and operator experience. J Periodontol 1989;60:67-72.

27. Fleischer HC, Mellonig JT, Brayer WK, Gray JL, Barnett JD. Scaling and root planing efficacy in multi-rooted teeth. $J$ Periodontol 1989;60:402-409.

28. Kepic TJ, O'Leary TJ, Kafrawy AH. Total calculus removal: An attainable objective? J Periodontol 1990;61:16-20.

29. Ciancio SG. Non-surgical periodontal treatment. In: Proceedings of the World Workshop in Clinical Periodontics. Chicago. The American Academy of Periodontology; 1989:II-1.

30. Badersten A, Nilvéus R, Egelberg J. Effect of nonsurgical periodontal therapy III. Single versus repeated instrumentation. $J$ Clin Periodontol 1984;11:114-124.

31. Ramfjord SP. Periodontal disease index (PDI). J Periodontol 1967;38:602-610.

32. Stambaugh RV, Dragoo M, Smith DM, Carasali L. The limits of subgingival scaling. Int J Periodontics Restorative Dent 1981;1(5): $30-41$.

33. Jones WA, O'Leary TJ. The effectiveness of in vivo root planing in removing bacterial endotoxin from the roots of periodontally involved teeth. $J$ Periodontol 1978;49:337-342.

34. Zander HA. The role of calculus in the etiology and treatment of periodontal disease. Acad Rev 1955;3(2):14-17.

35. Badersten A, Nilvéus R, Egelberg J. Effect of non-surgical periodontal therapy (IV). Operator variability. $J$ Clin Periodontol 1985;12:190-200.

36. Sherman PR, Hutchens Jr, LH, Jewson JG, Moriarty JM, Greco GW, McFall Jr, WT. The effectiveness of subgingival scaling and root planing. I. Clinical detection of residual calculus. $J$ Periodontol 1990;61:3-8.

Send reprint requests to: Dr. Gissela B. Anderson, The University of Texas, Health Science Center, Dental Branch, Department of Stomatology, Division of Periodontics, 6516 John Freeman Avenue, Room 309, Houston, TX 77030-3402.

Accepted for publication October 6, 1995. 